\title{
Evidence for multiple navigational sensory capabilities of Chinook salmon
}

\author{
Brian J. Burke ${ }^{1,2, *}$, James J. Anderson ${ }^{2}$, António M. Baptista ${ }^{3}$ \\ ${ }^{1}$ Fish Ecology Division, Northwest Fisheries Science Center, National Marine Fisheries Service, \\ National Oceanic and Atmospheric Administration, Seattle, Washington 98112, USA \\ ${ }^{2}$ School of Aquatic and Fishery Sciences, University of Washington, Seattle, Washington 98195, USA \\ ${ }^{3}$ Center for Coastal Margin Observation \& Prediction, Oregon Health \& Science University, Beaverton, Oregon 97006, USA
}

\begin{abstract}
To study the complex coastal migrations patterns exhibited by juvenile Columbia River Chinook salmon as they enter and move through the marine environment, we created an individual-based model in a coupled Eulerian-Lagrangian framework. We modeled 5 distinct migration strategies and compared the resulting spatial distributions to catch data collected during May and June in 3 years. Two strategies produced fish distributions similar to those observed in May, but only one also produced the observed June distributions. In both strategies, salmon distinguish north from south (i.e. they have a compass sense), and they control their position relative to particular landmarks, such as the river mouth. With these 2 abilities, we posit that salmon follow spatially explicit behavior rules that prevent entrapment in strong southward currents and advection offshore. Additionally, the consistent spatio-temporal distributions observed among years suggest that salmon use a clock sense to adjust their swim speed, within and among years, in response to progress along their migration.
\end{abstract}

KEY WORDS: Chinook salmon · Oncorhynchus tshawytscha $\cdot$ Migration · Navigation · Individualbased model $\cdot$ Behavior

\section{INTRODUCTION}

Our understanding of salmonid behavior and ecology during ocean residence is limited relative to that of other life-history stages (Hartt \& Dell 1986, Quinn 2005). However, for many individuals, ocean residence represents the longest stage of the life history. For example, Chinook salmon Oncorhynchus tshawytscha typically spend the first year in freshwater and then 1 to 5 yr in the Pacific Ocean before returning to spawn. Yearling Chinook salmon from the Columbia River enter the ocean and quickly migrate north (Peterson et al. 2010). Although general migration patterns are known (Weitkamp 2010, Tucker et al. 2011) and environmental correlates have been proposed (Bi et al. 2007, Burla et al. 2010a, Peterson et al. 2010, Burke et al. 2013), a comprehensive under-

\footnotetext{
*Corresponding author: brian.burke@noaa.gov
}

standing of the early ocean ecology and migration behavior of these juvenile salmon is missing.

One of the more difficult aspects of studying juvenile salmon ocean ecology is understanding the behavioral responses of these fish to external stimuli. For example, what cues do salmon use as aids during migration? Do fish make behavioral decisions based on local environmental conditions, so as to maximize their short-term growth rate? This would be a logical objective, given that mortality during early ocean residence is often size-dependent (Healey 1982, Good et al. 2001, Moss et al. 2005, Cross et al. 2009). Or have salmon evolved a northward migration strategy that relies on large-scale navigational aids, as has been shown for other animals (Wiltschko \& Wiltschko 1995, Papi 2006)? Although Alaskan coastal waters tend to be more productive than those off Oregon

() The authors 2014. Open Access under Creative Commons by Attribution Licence. Use, distribution and reproduction are unrestricted. Authors and original publication must be credited. 
and Washington, fish leaving the Columbia River have no cognitive knowledge of this fact.

The ability of salmon to consistently migrate to relatively specific locations, both as smolts and adults, has driven a large body of research. Salmon appear to use multiple cues, depending on the cue availability and the stage of migration (Dittman \& Quinn 1996, Quinn 2005). Groot (1965) first demonstrated that salmon use celestial cues for orientation but switch to 'some as yet unknown set of reference cues' as cloud cover increases. A series of experiments on sockeye salmon fry and smolts (Quinn 1980, Quinn et al. 1981, Quinn \& Brannon 1982) then revealed that, in the absence of alternative information, salmon oriented using the Earth's magnetic field; an ability found in a wide range of animals (Wiltschko \& Wiltschko 1995, Papi 2006, Lohmann et al. 2007). Indeed, recent work has identified magnetite-based magnetoreceptors in both salmon and trout (Kirschvink et al. 1985, Walker et al. 1988, 1997) as well as the use of the magnetic field in adult salmon during their return migration (Bracis \& Anderson 2012, Putman et al. 2013). Yet, as discussed by Friedland et al. (2001), our understanding of the relative role of these reference systems is still limited, particularly in the marine environment.

Willis (2011) distinguishes 2 general processes involved in migration: navigation is movement toward a goal outside of the sensory environment of an animal, and orientation is a directional response to local conditions (it should be noted that multiple definitions exist in the literature). By this definition, navigation requires a compass sense, while orientation may only require knowledge of ambient environmental conditions (e.g. an animal could orient relative to a temperature or salinity gradient). Burke et al. (2013) found that the response to (unspecified) large-scale variables, such as the sun or Earth's magnetic field, was stronger than the response to local environmental cues, which suggests that salmon primarily use navigation in their migrations. However, orientation to local conditions is also suggested by the high correlation between yearling Chinook salmon catches and local environmental conditions (Bi et al. 2007, Burla et al. 2010a, Yu et al. 2012, Burke et al. 2013).

To explore in more detail the importance of global navigation and local orientation in salmon migration behavior, we simulated fish movement through a virtual environment using an individual-based model (IBM) in a coupled Eulerian-Lagrangian framework (similar models were reviewed by North et al. 2009, Kishi et al. 2011, Willis 2011, Byron \& Burke in press). An individual fish makes thousands of behavioral decisions every day based on its environment, condi- tion, and genetic makeup. We simulated these decisions and the resulting movement of individual fish using prescribed behaviors in response to a dynamic physical environment. By integrating specific behavioral responses over a time series of environmental conditions experienced by the fish, we identified which behaviors produced realistic fish trajectories and final locations.

Using this tool, we tested a suite of plausible behaviors to characterize the effect of various orientation and navigation cues on the spatio-temporal distribution of juvenile salmon in the marine environment. Because of the complexity of migratory behavior and cues that direct migration, our aim was to eliminate some behaviors and cues as infeasible while identifying others that may be significant. In this way, our goal was to reduce the set of possible factors that need to be considered when studying salmonid migration and studying how existing migratory patterns may respond to local and global changes in the marine environment.

\section{MATERIALS AND METHODS}

A number of movement-modeling frameworks (e.g. reaction-diffusion equations) are inadequate to represent the complex coastal currents and concomitant ocean migration behaviors employed by salmon. We therefore used a combination of Eulerian and Lagrangian frameworks to simulate fish movement through a virtual environment (Willis 2011). Specifically, we used output from a Eulerian hydrodynamic model as the virtual environment (rather than dynamically simulating fish movement within the hydrodynamic model) and created a Lagrangian IBM that generated individual fish movements and behaviors within the environment.

After modeling fish with individualized responses to the environment, we summarized the set of modeled individuals to determine population-level spatio-temporal distributions. Simulations were implemented in the Python language (PSF 2013). Below, we describe the salmon data used in the simulations, the hydrodynamic model that generated the virtual environment, the details of the IBM, and, finally, how we analyzed the results.

\section{Salmon catch data}

Several distinct stocks of Chinook salmon from the Columbia River Basin, western USA, migrate as year- 

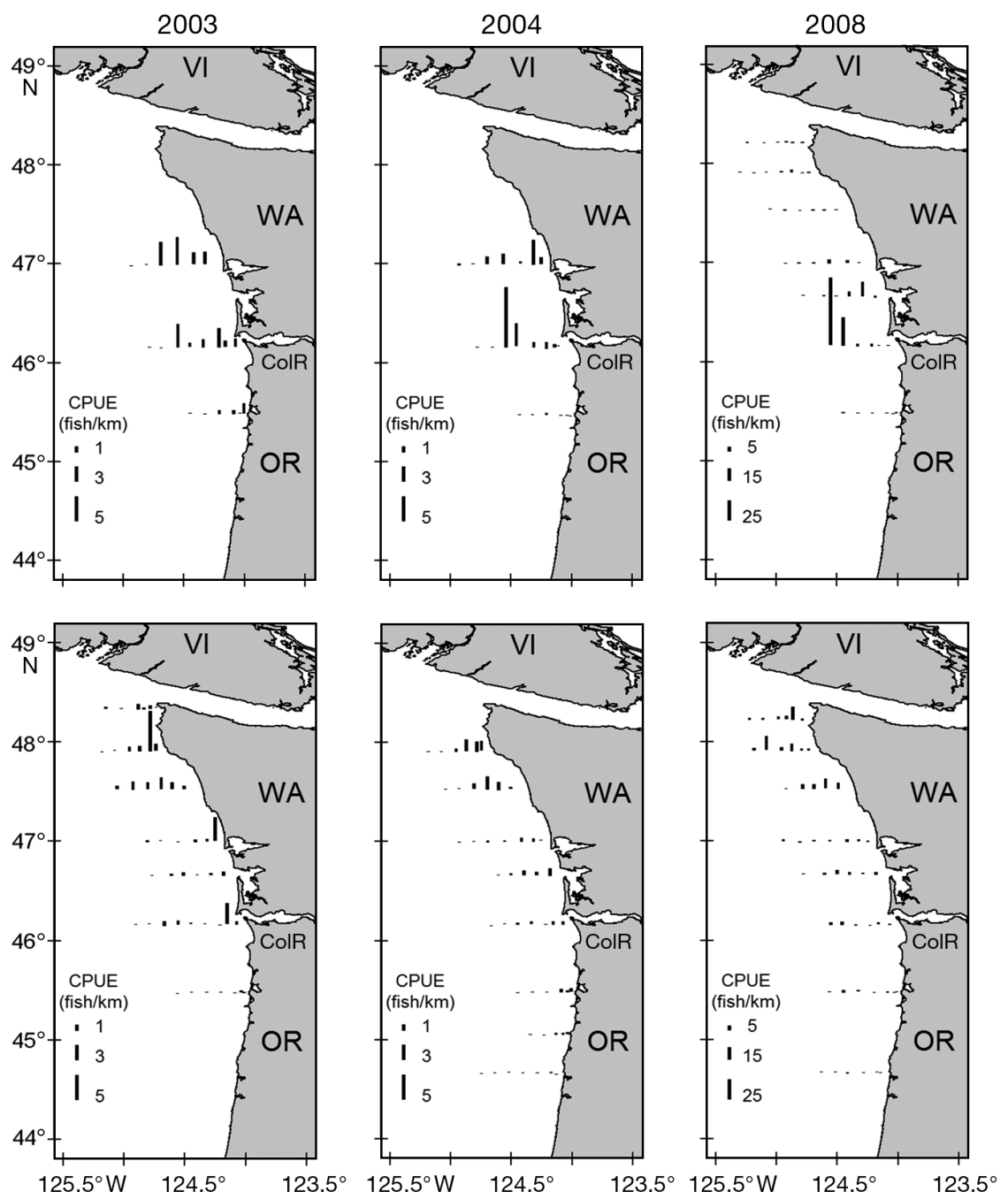

Fig. 1. Catch per unit effort (CPUE) of yearling Chinook salmon along the northwestern US coast in May (top) and June (bottom) of 2003, 2004, and 2008. ColR: Columbia River; VI: Vancouver Island, Canada; WA: Washington, USA; OR: Oregeon, USA

lings (Waples et al. 2004, Quinn 2005, Burke et al. 2013). On entering the ocean, these stocks generally initiate a rapid northward migration (Peterson et al. 2010; Fig. 1) against prevailing coastal currents (Hickey \& Royer 2001). Although the stocks exhibit distinct spatio-temporal distributions (Burke et al. 2013), we consider the aggregate Chinook salmon run for our analysis and not stock-specific differences.

We used yearling Chinook salmon catch data from an ongoing NOAA Fisheries survey (Peterson et al. 2010) in which juvenile salmon were collected using a pelagic rope trawl with a mouth opening of $30 \mathrm{~m}$ wide by $20 \mathrm{~m}$ deep. The survey includes 3 to 10 eastwest transects from La Push, WA, to Newport, OR. Stations along each transect were sampled annually for $12 \mathrm{yr}$ in late May, late June, and late September.
Due to limited availability of hydrodynamic model output and the quantity and quality of data on juvenile salmon distributions, we restricted the analysis to ocean entry years 2003, 2004, and 2008, which represent a range of both salmon survival rates and oceanographic conditions (Tomaro et al. 2012). Further details on the survey methods were reported by Brodeur et al. (2005).

\section{Hydrodynamic modeling system}

Understanding the ocean migration routes of Columbia River salmon requires quantitative knowledge of the circulation during their residence in the coastal marine habitat. We defined ocean circulation near the Columbia River and the coastal ocean from 1 March through 30 September using the Virtual Columbia River modeling system (CMOP 2013), which provides a high-resolution description of 3-dimensional (3D) river-toocean circulation and water properties in the Columbia River and plume (Baptista et al. 2008, Burla et al. 2010b).

We used simulations archived as database DB22 in the Virtual Columbia River. State variables of DB22 (water level, temperature, salinity, and $3 \mathrm{D}$ velocities) were computed every $90 \mathrm{~s}$ and stored every $15 \mathrm{~min}$ in either the centers (water level and vertical velocity), the nodes (salinity and temperature), or the side centers (horizontal velocity) of the triangular elements of the computational grid. Grid element areas varied from $>0.002$ to $<480 \mathrm{~km}^{2}$ (mean: $8.5 \mathrm{~km}^{2}$ ). The computational grid extended from Beaver Army Terminal near Quincy, Oregon (in the tidal freshwater part of the Columbia River estuary), to marginally beyond the Oregon and Washington continental shelves; this domain encompasses the rectangular box bounded by $42.0^{\circ} \mathrm{N}, 125.5^{\circ} \mathrm{W}, 49.0^{\circ} \mathrm{N}$, and $124.0^{\circ} \mathrm{W}$ used in the present study. Because simulated fish could exist anywhere in a continuous volume, we interpolated oceanic conditions to the fish locations.

The computational engine underlying the Virtual Columbia River modeling system was SELFE (semi- 
implicit Eularian-Lagrangian finite-element), a baroclinic circulation model based on the solution of 3D shallow water equations (Zhang \& Baptista 2008). These consisted of a continuity equation, conservation equations for momentum, salinity, and heat, and an equation of state, which used a finite-element method applied on an unstructured, 3-node triangular grid. The skill of these simulations had been previously assessed through quantitative comparison against observations of water level, salinity, and temperature from the Science and Technology University Research Network (SATURN) collaboratory (Baptista et al. 2005, Burla et al. 2010b).

\section{Individual-based model}

We describe the IBM using the overview, design concepts, and details (ODD) protocol of Grimm et al. (2006, 2010). The overview portion includes the purpose of the model, the state variables and scales used, and an overview of the processes and scheduling. We then describe the details of initialization, model input, and several submodels.

\section{Overview}

Purpose. After salmon leave the Columbia River, there is little known about the routes taken during their initial migration, and even less is known about the behaviors they employ during this stage. This model is intended to (1) distinguish between feasible and unrealistic behaviors, given the constraints of coastal currents, fish size, and post-smolt migration timing, and (2) evaluate various migration behaviors by comparing simulated spatio-temporal distributions to observed distributions.

State variables and scales. Environmental state variables included temperature, salinity, 3D flow, and water depth. For some simulations, distance from shore and chlorophyll a concentration were also explicitly used as a driving variable.

Fish were assigned an ocean entry date and an initial 3D location, which was updated at every $15 \mathrm{~min}$ time step of the simulation. Fish size was also updated at every time step using a standard bioenergetics model with parameters for Chinook salmon (Hewett \& Johnson 1992). Consumption was modeled using a proportion of maximum daily consumption, or P-value (a size- and temperature-dependent variable), and each fish kept its randomly assigned P-value for the duration of the simulation. Similarly, if a simulation employed active swimming (Table 1), assigned swim speeds (body lengths [BL] per second) were maintained for the duration of the simulation, such that speed relative to the water increased as fish grew.

Process and scheduling. Each simulation started at 00:15 h on 1 April and ran through midnight on 1 July. During each time step, fish first grew according to the bioenergetics model, local temperature, and assigned P-value. Fish then moved to a new location, where they stayed until the next time step. The growth and movement of each fish was independent of that of other fish as there was no direct or indirect interaction among individuals. While mortality is high during the early ocean stage (Pearcy 1992, Beamish

Table 1. Simulated movement behaviors used in the individual-based model. For each of the 3 yr, 10000 particles were simulated using each of these behaviors

\begin{tabular}{|c|c|c|}
\hline $\begin{array}{l}\text { Simulated } \\
\text { behavior ID }\end{array}$ & Behavior & Description \\
\hline $\mathrm{PP}$ & Passive particle & No active swimming, passively drift horizontally and vertically with ocean currents \\
\hline OT & $\begin{array}{l}\text { Optimize } \\
\text { temperature }\end{array}$ & $\begin{array}{l}\text { Migrate vertically each time step to the depth closest to } 12^{\circ} \mathrm{C} \text {; optimal temperature } \\
\text { during the first summer at sea is probably between river temperatures }\left(\sim 15^{\circ} \mathrm{C}\right) \text { and } \\
\text { temperatures observed for subadults }\left(8 \text { to } 12^{\circ} \mathrm{C} \text {; Hinke et al. 2005); passive in the }\right. \\
\text { horizontal direction }\end{array}$ \\
\hline $\mathrm{F} 2$ & Optimize flow & $\begin{array}{l}\text { Similar to selective tidal transport; migrate vertically each time step to depth of } \\
\text { greatest northward flow within the top } 20 \mathrm{~m} \text {; passive in the horizontal direction }\end{array}$ \\
\hline PR & Positive rheotaxis & $\begin{array}{l}\text { Swim at a constant rate each time step in the same horizontal direction as the ocean } \\
\text { current; passive in the vertical direction }\end{array}$ \\
\hline SX & $\begin{array}{l}\text { Active northward } \\
\text { biased migration }\end{array}$ & $\begin{array}{l}\text { Actively swim northward along the coast; passive in the vertical direction. Separate } \\
\text { simulations (S3, S5, and S9) were run using swim speeds of } X=0.3,0.5 \text {, or } 0.9 \text { body } \\
\text { length } \mathrm{s}^{-1} \text {, respectively. Mean swim direction was } 8^{\circ} \text { west of north. An Ornstein- } \\
\text { Uhlenbeck process was used to alter the swim angle each time step to bring fish } \\
\text { back towards the center of the migration route at } 28.5 \mathrm{~km} \text { from shore. }\end{array}$ \\
\hline
\end{tabular}


\& Mahnken 2001), we had insufficient information to partition mortality spatially or temporally. Therefore, all simulated fish were considered survivors of the first $3 \mathrm{mo}$ in the marine environment.

\section{Design concepts}

Basic principles. Optimal swim speed for both travel and foraging is size-dependent (Ware 1978), as are many ecological processes acting on individuals (Arendt 1997, Sogard 1997). We included a bioenergetics model to allow individual growth throughout the simulation, such that all size-dependent processes in the model (e.g. growth and swimming speed) affected fish appropriately.

As this model describes the migration of animals through a dynamic environment, we tested behaviors related to both movement theory and habitat selection. Among the behavioral rules, we included passive drift, diffusion, and directed migration. In other rules, we explicitly tested habitat selection using multiple temperature-based behaviors as well as some behaviors involving distance from shore (Table 1).

Adaptation. Columbia River yearling Chinook salmon are consistently captured in a narrow east-west band (mean distance from shore $=28.5 \mathrm{~km}, \mathrm{SD}=$ $7.6 \mathrm{~km}$ ) along the Washington coast (Peterson et al. 2010), but our efforts to mechanistically model such a narrow migration corridor were unsuccessful. As the northward migration was our primary focus, we simplified the model by imposing an attraction to a specific east-west location. For simulations involving behavior SX (behaviors are described below and in Table 1), we used an Ornstein-Uhlenbeck process to adjust the swim angle. In this framework, the greater the distance between a fish and the line of attraction, the more its swim angle was shifted back toward the line. This resulted in swim angles of $\sim 320^{\circ}$ for fish on the shoreline and $\sim 45^{\circ}$ for fish $80 \mathrm{~km}$ offshore. Although the mechanism by which fish maintain their east-west location is unknown, inclusion of this line of attraction was necessary to keep simulated fish from migrating into land or far offshore. Mean distance from shore for yearling Chinook salmon sampled over $12 \mathrm{yr}$ (Peterson et al. 2010) was $28.5 \mathrm{~km}$, and we used this as the line of attraction.

Sensing and prediction. Ambient conditions such as temperature and flow were used to determine fish behavior. Simulated fish had no explicit knowledge of environmental conditions at any spatial coordinates other than their immediate location, with the exception of vertical structure used to optimize verti- cal temperature (OT) and flow (F2). For these behaviors, fish selected specific attributes from within the water column. The thermocline was usually shallow $(\sim 10 \mathrm{~m})$, and it is certainly feasible that fish regularly make short vertical movements within a 15 min time step to determine vertical temperature or flow profiles.

On a larger temporal and spatial scale, we postulated that fish are inherently inclined to migrate north, which implies a genetically selected propensity to migrate to regions that have historically allowed higher growth and/or survival. For these simulations, we made 2 assumptions regarding spatial information: (1) fish had a compass sense and therefore knew what direction was north (Quinn \& Groot 1983, Quinn 1991), and (2) fish knew their distance from shore. For the latter assumption, we do not know the nature of the cue, but it is likely to involve one or more oceanographic features.

Stochasticity. We started all simulations with the same random number seed in the Python language, so that all randomly drawn variables (initial length, ocean entry date, P-value, and initial depth) were identical among simulations. Therefore, each simulation (within a year) tested the same initial set of 10000 randomly drawn fish with the only difference among simulations being fish behavior (see 'Initialization').

Observation. We stored all initial data (length, location, P-value, and swim speed) to files. Every $12 \mathrm{~h}$ of simulated time, we recorded the location and length of all fish. All data were imported into R software for analysis (R Development Core Team 2011).

\section{Details}

Initialization. At the start of a simulation, we generated 10000 virtual fish and assigned initial values for all state variables. Fish sizes $(\mu=155 \mathrm{~mm}, \mathrm{SD}=$ $15 \mathrm{~mm}$ ) and ocean entry dates $(\mu=15$ May, $\mathrm{SD}=$ $10 \mathrm{~d}$ ) were drawn randomly from normal distributions (Table 2), roughly matching empirical data collected in the Columbia River estuary (Weitkamp et al. 2012). Fish initiated migrations just inside the Columbia River mouth (latitude $46.2482^{\circ} \mathrm{N}$, longitude $-124.0759^{\circ} \mathrm{W}$ ) at randomly (uniformly) assigned depths within the top $10 \mathrm{~m}$. The proportion of the maximum daily consumption rate (P-value) of each fish was drawn from a $\log$-normal distribution $(\mu=\log (0.5), \mathrm{SD}=0.5)$.

Input. All input data were obtained from the hydrodynamic modeling system described above (Zhang \& Baptista 2008) except chlorophyll $a$, which was obtained from a satellite via the NOAA CoastWatch Program (PFEL 2013). 
Table 2. Parameters and variables of the individual-based model. $\sim \mathrm{N}, \sim \mathrm{LN}$ and $\sim$ uniform are approximately normal, log-normal and uniform distributions, respectively

\begin{tabular}{|lll|}
\hline Attribute & Value or distribution & Source \\
\hline Release date & $\sim \mathrm{N}(\mu=$ May 15, SD $=10 \mathrm{~d})$ & Weitkamp et al. (2012) \\
Fish length & $\sim \mathrm{N}(\mu=155 \mathrm{~mm}, \mathrm{SD}=15 \mathrm{~mm})$ & Weitkamp et al. (2012) \\
Energy content & $0.0000152 \times$ Length \\
Bioenerge & Hewett \& Johnson (1992) \\
Initial location & $\sim \mathrm{LN}(\mu=\log (0.5), \mathrm{SD}=0.5)$ & \\
& Latitude $=46.248^{\circ} \mathrm{N}$ & \\
& Longitude $=124.076^{\circ} \mathrm{W}$ & \\
& Depth $\sim$ uniform $(0-10 \mathrm{~m})$ & \\
\hline
\end{tabular}

Growth submodel. We modeled fish growth using a standard bioenergetics model parameterized for Chinook salmon (Hewett \& Johnson 1992). In each 15 min time step, fish first instantaneously grew and then moved. As most bioenergetics models are parameterized for a $24 \mathrm{~h}$ time step, we divided all rate constants (e.g. consumption) by 96 to match our $15 \mathrm{~min}$ time step. To maintain a widening gap between the largest and smallest fish throughout the simulation, maximum daily consumption (P-values) did not change within a simulation. This also reduced the stochasticity of the model and allowed comparisons of individual fish among simulations (results not shown), where the only difference between the fish was the assigned behavior (Table 1).

Movement submodel. We defined 5 distinct behavioral rules (Table 1). Swimming through water is energetically expensive, and our set of migration strategies was chosen to determine whether simple and efficient behaviors were sufficient to simulate the observed fish distributions or whether more complex and energetically costly behaviors were required. The null behavior, passive particle (PP), assumed fish were passive in 3 dimensions (Willis \& Hobday 2007, Brochier et al. 2008) and served as a particle tracer of ocean currents.

For the optimum temperature behavior (OT), fish maintained the optimum temperature for growth, which we assumed to be $12^{\circ} \mathrm{C}$ based on results from Hinke et al. (2005), via vertical movement during each time step. Horizontal movement for this behavior was passive. Similarly, there was no active horizontal movement for the optimizing flow behavior (F2), in which fish selectively adjusted their depth within the top $20 \mathrm{~m}$ to maximize northward movement (see Burke et al. 2013 for justification of the $20 \mathrm{~m}$ cutoff). Essentially, fish move vertically into slow water when flows are southerly and into fast water when flows are northerly, thus maximizing net northward displacement without active horizontal swimming (Lacroix \& McCurdy 1996). Using local currents to aid movement has been shown for many migrating species, including tuna, moths (Alerstam et al. 2011), and Atlantic salmon Salmo salar (Thorstad et al. 2012). To employ the selection of northward currents in this behavior, animals required a compass sense.

We simulated 2 behaviors that involved active horizontal movement. The positive rheotaxis (PR) behavior was similar to that used in other coupled oceanographic and IBM, which have shown that swimming with or against currents could be a successful migration strategy (Booker et al. 2008, Mork et al. 2012). During the positive rheotaxis simulations, fish maintained a swim speed of $0.5 \mathrm{BL} \mathrm{s}^{-1} \mathrm{di}-$ rectly into the prevailing current. Although we report results only for positive rheotaxis, we also ran simulations using negative rheotaxis. However, ocean currents in this region are predominantly southern in the springtime (Hickey \& Royer 2001), and therefore, negative rheotaxis was obviously not a viable strategy.

Finally, we simulated active northward swimming (SX), independent of local environmental conditions. Three swim speeds were individually simulated $(0.3$, 0.5 , and $0.9 \mathrm{BL} \mathrm{s}^{-1}$ ) at a mean angle of $8^{\circ}$ west of north (approximately along the coastline), adjusted each time step according the Ornstein-Uhlenbeck model described above. Like the behavior to optimize flow, the active northward migration behavior required that fish have a compass sense.

\section{Analysis}

Final locations of simulated fish were compared to the spatial distribution of yearling Chinook salmon caught during the NOAA Fisheries surveys (Fig. 1; Brodeur et al. 2005). To select feasible behaviors, we used a combination of visual comparisons and simple summary metrics (e.g. mean final latitude). Our goal was to provide relative support for or against migration behaviors rather than to prove that salmon use any particular behavior. Moreover, the simulated data (a point process) and the observed data (density estimates at discrete locations) were not directly comparable quantitatively (most spatial statistics require either a point process or a density estimate [Bivand et al. 2013]; we are not aware of statistical methods to compare the 2 types directly).

We summarized simulated data from 26 May and 26 June, corresponding to the middle dates of re- 
search cruises each year. For these summaries, we calculated the centroid of the population, defined as the mean location of the 10000 fish in each simulation, and the spread about the centroid. To account for anisotropy in final locations, we estimated variance in the final location in 2 directions. For this estimate, we used principal component analysis to identify the axis with the greatest variance (Woillez et al. 2007), which was often somewhat parallel with the coastline, and calculated the variance in this direction as well as the direction perpendicular to it. Spatial metrics were calculated in meters, the unit of the hydrodynamic model (Oregon State Plane projection for spatial coordinates, epsg: 32 026, units $=\mathrm{m}$ ), and converted to latitude and longitude for reporting and mapping. Because the final depth of simulated fish from all behaviors was primarily near the surface (data not shown), and this depth matched the depths observed in trawl samples, no further analyses or comparisons were done with fish depth.

To better understand the relationship between the final location of fish and model variables, we compared final locations on 26 June of each year to several model parameters, such as initial length, ocean entry date, and the bioenergetics P-value. Fish length (and therefore, any parameters related to growth) by definition had no effect on location for any behaviors in which fish were not actively swimming (i.e. passive particle, optimal temperature, and optimal flow). Migration date had the potential to influence final location in all simulations because currents near the mouth of the Columbia River and coastal ocean vary considerably on daily and weekly time scales (Hickey et al. 2005, 2010, Burla et al. 2010b).

\section{RESULTS}

The behaviors that produced spatial distributions most similar to those observed were different in May and June. For May, behaviors of optimized flow and active northward swimming (at all 3 speeds) fit the observed distributions relatively well (Fig. 2). This suggested that salmon either used a depth-modification behavior to avoid the strongest southward ocean currents or actively migrated north. For simulations using active northward swimming, the swim speed required to match empirical data differed by year. In 2003, when southward currents were relatively strong, a swim speed of $0.9 \mathrm{BL} \mathrm{s}^{-1}$ (S9) matched well with observed distributions. In contrast, in 2004 and 2008, swim speeds of only 0.3 and $0.5 \mathrm{BL} \mathrm{s}^{-1}$ (S3 and S5) were required to match the observed distributions.
Although optimizing northward flow (F2) allowed a substantial number of simulated fish to move north as late as May, when coastal currents were relatively weak, it was not a sufficient strategy to maintain northward movement through June. Only active northward swimming produced a reasonable spatial overlap with the observed distributions (Fig. 2; see Figs. S1-S6 in the Supplement at www.int-res.com/articles/suppl/ b020p077_supp.pdf). Additionally, swim speeds that produced the best results in June matched those that did so in May within each year simulated.

The Ornstein-Uhlenbeck process was employed to keep simulated fish from migrating too far inshore or offshore during simulations of active northward swimming and resulted in a realistic east-west distribution off the Washington coastline (mean distance from shore observed over $12 \mathrm{yr}$ of sampling was $28.5 \mathrm{~km}$ [Peterson et al. 2010] with an SD of $7.6 \mathrm{~km}$ ). Swim angles varied considerably within and among years (Fig. 3) and were highly dependent upon location (particularly whether fish were north or south of the Columbia River). Although we expected this variability given the complex nature of the Columbia River plume (Hickey et al. 2005, MacCready et al. 2009), this aspect of the model was not directly validated, and results should not be treated as direct evidence of a particular behavior.

As is true most years during spring and summer, ocean currents were predominately southward in the 3 years included in this study, and simulated fish with PP behavior mostly ended up south of the Columbia River (Fig. 4, Table 3). By June, most simulated fish were $>2^{\circ}$ latitude south of the centroid of the observed distribution. For all PP comparisons (yearmonth combinations), variability in north-south location was 2- to 5 -fold greater for simulated fish than for observed fish.

Simulated fish that adjusted vertical depth to a temperature of optimum growth (OT) ended up much further south than fish in the observed distributions in both months and all years (Table 3). While most of these fish remained in the top $40 \mathrm{~m}$ of the water column, suggesting that the behavior was logistically feasible, their final locations in May and June strongly suggested that movement based on optimal temperature for growth is not a feasible behavior for migrating yearling Chinook salmon. Similarly, positive rheotaxis (PR) resulted in most of the simulated fish moving south of the Columbia River (Fig. 4). However, the difference in mean latitude between observed and simulated fish was less for fish using the positive rheotaxis than for fish using the optimal temperature behavior. In both 

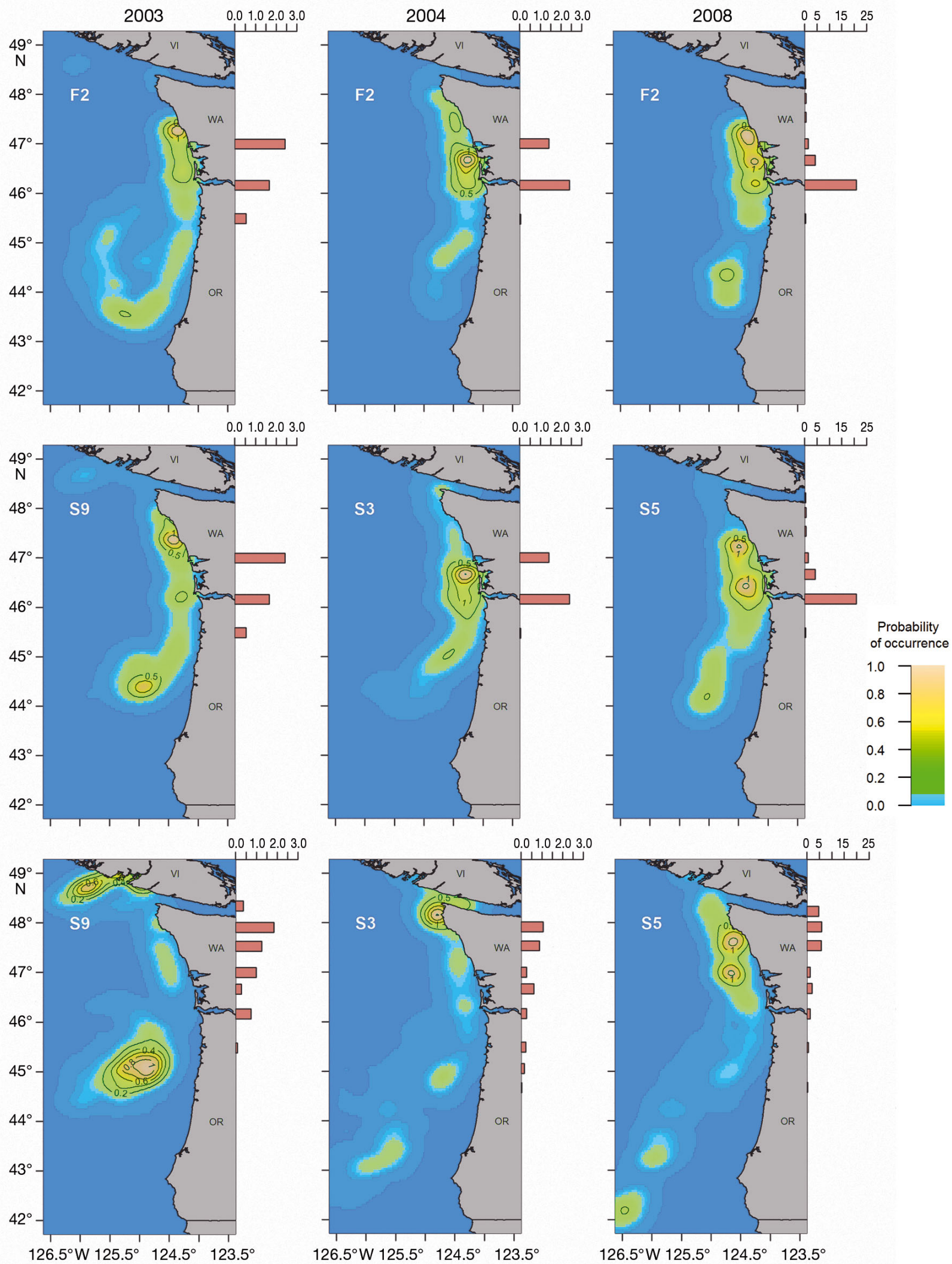

Fig. 2. Smoothed probability of occurrence of simulated fish from the best models for May (top and middle) and June (bottom) of 2003, 2004, and 2008. Bars represent the average catch per unit effort (fish km $\mathrm{km}^{-1}$ ) for each transect from the trawl survey. Respective active northward migration rates were $0.9,0.3$, and 0.5 body length $\mathrm{s}^{-1}$ for 2003, 2004, and 2008. See Table 1 for details on behavior codes (F2, S3, S5, and S9) 


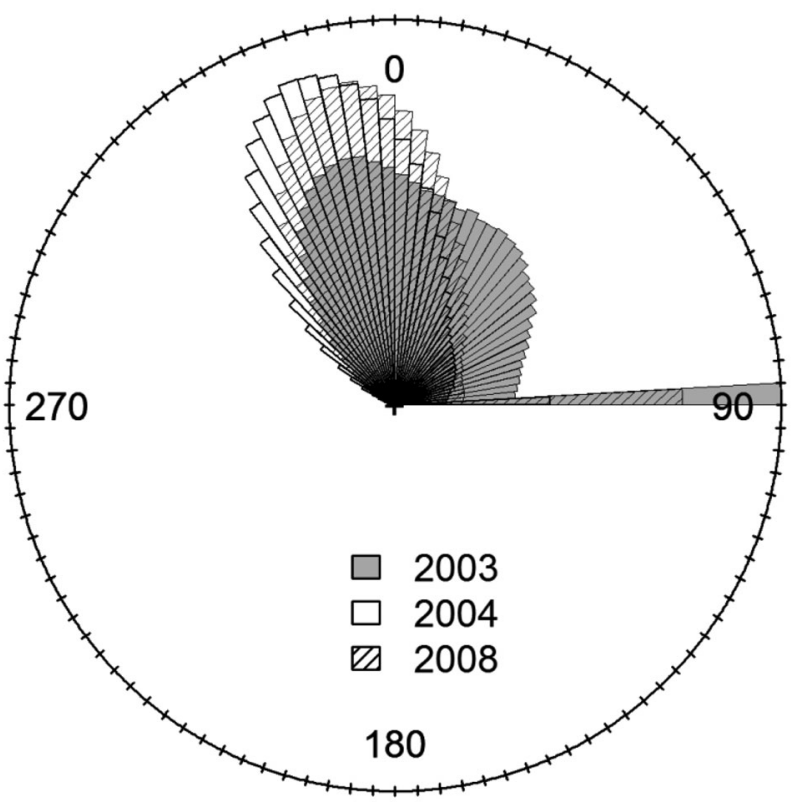

Fig. 3. Frequency of turn angles by fish throughout the entire simulation. Results are from simulations using the active northward migration behavior and the best swim speed for each year: 0.9 body lengths (BL) s${ }^{-1}$ in 2003, $0.3 \mathrm{BL} \mathrm{s}^{-1}$ in 2004, and $0.5 \mathrm{BL} \mathrm{s}^{-1}$ in 2008. The large proportion of fish swimming at $90^{\circ}$ is due to fish south of the Columbia River that were advected offshore and were trying to compensate

cases, we did not see a large effect of fish size on movement and distribution.

In all simulations, including those that best matched observed spatial patterns, some fish were pushed south of the Columbia River just after ocean entrance. Although the proportion of fish pushed south varied by year and behavior (Fig. 4), very few fish were able to counter the strong southward flows, upwelling-driven offshore currents, and eddies that carried them offshore. In some cases, these advected fish had a large influence on summary metrics, such as mean final location (Table 3, see Figs. S1-S6 in the Supplement). Interestingly, the subset of fish advected south was not influenced to a large extent by length, growth, or ocean entry date (see Fig. S7 in the Supplement).

\section{DISCUSSION}

The simulations suggest that Columbia River yearling Chinook salmon use at least 2 sensory modalities during migration: a compass sense and a clock sense. In addition, there is some tentative evidence that fish use a map sense, although other modalities may be involved. Evidence for each modality arises from different aspects of the simulations, as described below.

\section{Compass sense}

For most of the behaviors modeled, the predominantly southward flowing coastal currents prevented simulated fish from migrating north. In fact, most behaviors resulted in fish moving quite far south and offshore of the Oregon coast. Counter to our initial expectations, positive rheotaxis alone was insufficient to produce northward migration since the coastal currents were too complex to produce a consist cue for northward movement. The only behaviors that produced the observed northern distributions of fish were optimization of northward flows via vertical migration (F2) and/or active northward swimming (SX). Since both of these behaviors require that fish sense the direction north, we concluded that salmon use a compass sense during their marine migration.
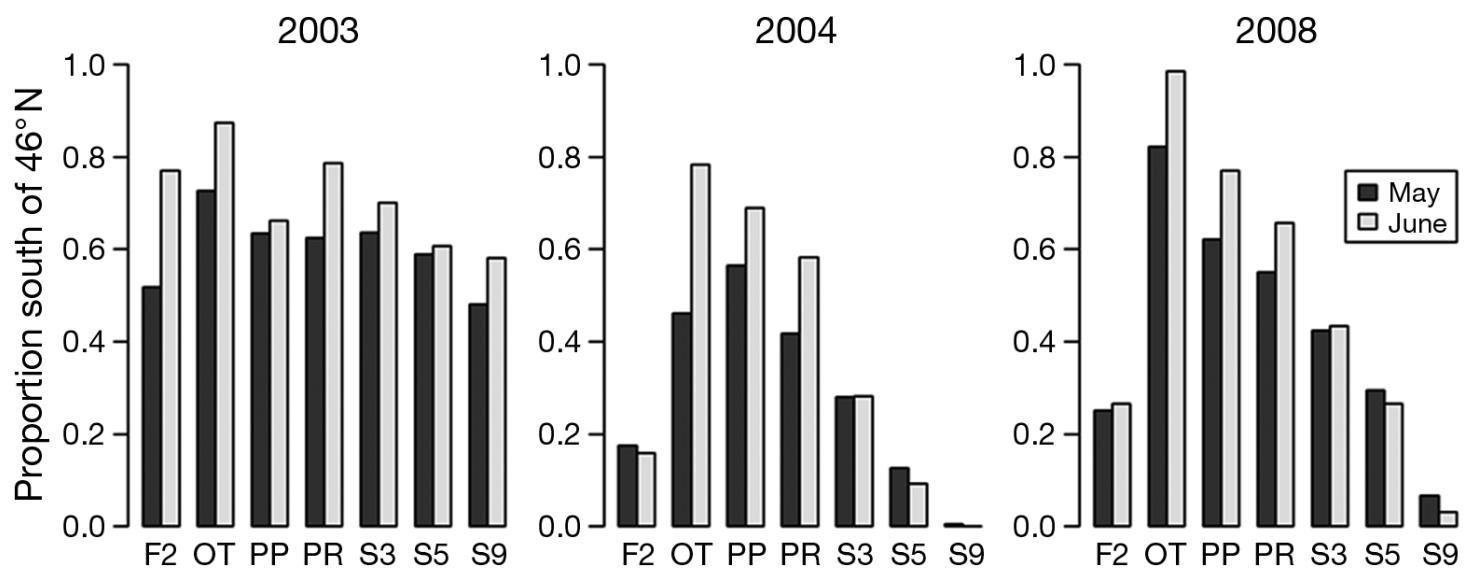

Fig. 4. Proportion of simulated fish south of latitude $46^{\circ} \mathrm{N}$ according to behavior for May and June of 2003, 2004 , and 2008. See Table 1 for behavior codes 
Table 3. Mean latitude $\left({ }^{\circ}\right)$ and standard deviation in the north-south direction $(\mathrm{km}$; in parentheses) of observed Chinook salmon Oncorhynchus tshawytscha (Observed) and simulated fish (all other parameters, see Table 1 for details). For observed data, we calculated mean and SD by weighting the station locations by catch per unit effort

\begin{tabular}{|c|c|c|c|c|c|c|}
\hline & \multicolumn{2}{|c|}{2003} & \multicolumn{2}{|c|}{2004} & \multicolumn{2}{|c|}{2008} \\
\hline & May & June & May & June & May & June \\
\hline Observed & $46.5(59.0)$ & $47.3(80.1)$ & $46.4(43.8)$ & $47.0(98.2)$ & $46.4(49.1)$ & $47.5(82.4)$ \\
\hline Passive particle & $45.2(135)$ & $44.8(194)$ & $45.6(100)$ & $44.7(211)$ & $45.5(110)$ & $44.2(198)$ \\
\hline Optimize temp. & $44.8(122)$ & 44.1 (139) & $45.5(94)$ & $44.6(112)$ & $45.3(91)$ & $43.8(123)$ \\
\hline Optimize flow & $45.6(150)$ & $45.0(130)$ & $46.5(92)$ & $47.3(175)$ & $46.3(110)$ & $46.0(186)$ \\
\hline Positive rheotaxis & $45.3(116)$ & $44.8(135)$ & $46.0(58)$ & $45.6(128)$ & $45.7(86)$ & $45.2(143)$ \\
\hline \multicolumn{7}{|c|}{ Active northward migration (body lengths $\mathrm{s}^{-1}$ ) } \\
\hline 0.3 & $45.4(129)$ & $45.5(132)$ & 46.3 (93) & 46.8 (206) & 45.9 (114) & 45.4 (206) \\
\hline 0.5 & 45.6 (136) & 45.7 (115) & 46.7 (83) & $47.3(165)$ & $46.2(107)$ & $46.3(215)$ \\
\hline 0.9 & $46.0(140)$ & $45.7(132)$ & $47.2(73)$ & $48.0(74)$ & $47.0(76)$ & 47.7 (125) \\
\hline
\end{tabular}

\section{Clock sense}

The observed interannual variability in the spatial distribution of yearling Chinook salmon has been relatively small (Peterson et al. 2010, Weitkamp 2010), particularly in May, shortly after they entered the marine environment (Fig. 1). However, in the years included in the present study, the strength and direction of ocean currents varied considerably (see the passive particle simulation results in the Supplement [Figs. S1-S6] to get a sense of this variability). We propose that to achieve a stable spatial distribution within a highly variable current regime, fish must have a sense of time, i.e. clock sense, enabling them to adjust swimming behavior to achieve a consistent rate of migration. As expected under this scenario, the swim speed and swim angle required to match observed distributions varied among years. Given the abundant evidence regarding biological clocks in animal movement (e.g. Brady 1982, Pastor \& Artieda 1996), it is not surprising that salmon also employ a clock sense during migration.

\section{Map sense}

Growing evidence suggests that salmon have the capability to detect and respond to the Earth's magnetic field during ocean migration (Bracis \& Anderson 2012, Putman et al. 2013). In addition to a compass and clock sense, our results provide 2 indications that post-smolt salmon perceive their location in the ocean relative to some geo-referenced cues. First, yearling Chinook salmon maintain a relatively constant distance from shore, even though the east-west component of flow is highly variable. Because of this, the swim angle necessary for simulated fish to maintain a particular distance from shore was also highly variable (Fig. 3). However, it is unclear how salmon are able to maintain their narrow east-west distribution (SD = 7.6 km). Moreover, wind-driven upwelling events occur frequently and result in strong offshore currents, yet we rarely caught fish at our outermost sampling locations (Fig. 1), suggesting that salmon counteract the effect of upwelling-driven offshore currents. It is unclear whether salmon detect the eastward or westward movement of water directly or whether they are initially advected by the currents and detect their resulting change in location. The former could potentially be accomplished via small-scale movements to determine vertical gradients in flow, whereas the latter would indicate direct knowledge of position and support the notion of a map sense. Either way, the low variability in offshore distance is compelling evidence that fish behaviorally compensate for the dynamic east-west component of coastal currents.

A similar location-induced behavioral compensation could explain the apparent sharp southern boundary of yearling Chinook salmon from the Columbia River. Despite consistent sampling as far south as Newport, Oregon, very few fish from these stocks have been captured south of the river (Peterson et al. 2010, Burke et al. 2013). However, many simulated fish were caught in an eddy south of the Columbia River and quickly transported south and offshore. Even fish migrating at the fastest speeds tested $\left(0.9 \mathrm{BL} \mathrm{s}^{-1}\right)$ could not counter these ocean currents at times.

The presence of simulated fish south of the Columbia River mouth resulted in a latitudinal variance that was generally higher than that for observed fish (Table 3). One possible explanation for the discrepancy between simulated and observed latitudinal variance is that the observed fish exhibit more control than the modeled fish of their northward migration in relation to their geo-spatial position. For 
example, real fish may increase their swim speed $\left(>0.9 \mathrm{BL} \mathrm{s}^{-1}\right)$ if they are driven south of their migratory route. However, in this scenario, they must also decrease their speed once they return to the migration route and are on schedule. Otherwise, the increased swim speed would have simulated fish exceed the position of fish observed in June. Supporting this scenario, Tomaro et al. (2012) observed variable swim speed with early migrating individuals swimming slower than average and later migrants swimming slightly faster. In effect, we suggest that to avoid entrapment in large-scale eddies, fish require some perception of their position so they can adjust their swim speed and direction to maintain a migration schedule northward along the coast.

Unfortunately, the mechanisms driving the hypothesized adjustments in swim speed are unclear. Similar to the east-west component of their distribution described above, salmon may either detect the strong southward currents directly and alter behavior to avoid them, or they may detect that they have been advected south through the use of a map sense and increase northward movement. Of the 2 explanations, we believe that the use of positional information and a map sense is more likely for 2 reasons. First, the consistency in spatial distribution (Weitkamp 2010) requires that fish respond to the complex and highly dynamic ocean currents in and near the Columbia River plume in a precise manner. The Columbia River plume is particularly variable and often shifts direction on weekly or even daily time scales (Hickey et al. 2005, 2010, Burla et al. 2010b). Error in response to changing currents would propagate through time, resulting in fish dispersing farther off course throughout the migration, which is not supported by the empirical data. Second, salmon have been shown to possess the magnetoreceptors necessary for this sensory ability (Kirschvink et al. 1985, Walker et al. 1988), and evidence exists that adult salmon use a map sense during their homing migration in the ocean (Putman et al. 2013). If salmon indeed use a map sense to restrict movement away from the southern areas, it need only be a singlecoordinate system (Lohmann et al. 2007). For example, if salmon can detect the magnetic field inclination, they could determine whether they were north or south of the Columbia River by comparing the inclination at their present location to the inclination imprinted at the Columbia River mouth (see Putman et al. 2013). Although there is much literature on these sensory capabilities (Wiltschko \& Wiltschko 1995, Walker et al. 1997, Papi 2006, Lohmann et al. 2007), we cannot distinguish among particular mech- anisms (e.g. magnetic versus sun or celestial maps). Therefore, any conclusions from the present work about salmon using a map sense during migration are still speculative and require further research.

\section{Behaviors that did not work}

Coastal currents are highly dynamic in space and time, and our simulations indicated that a simple response to currents (e.g. rheotaxis) would not guarantee northward movement. Our analysis suggests that the consistent distributions of juvenile salmon along the coast of Washington in spring and summer can only be achieved if fish use northward-biased migration behaviors, at least as a component of their migratory behavior.

There seemed to be a limit to how much selective transport could aid in migration. In optimal flow (F2) simulations, fish adjusted their depth to maximize northward movement, and the resulting distributions matched the observed distribution of salmon for May but not for June. This is primarily because southward flow intensified during the spring and summer and eliminated the ability to passively move north at most depths. Simulations therefore tended to clump the fish that had moved north into a very small cluster off the coast of southern Washington in June, contrasting with the larger spread in observed distributions.

In simulations not included here, we evaluated a 'selective transport' behavior involving larger vertical migrations, wherein fish were able to move further north by May and June. However, fish must make use of the entire water column to match the June distributions (e.g. hold station at the bottom during southward moving phases and move to the surface during the northward phases). Because these ocean migrants primarily use the surface waters (Emmett et al. 2004), we ruled out 'selective transport' as a sole migration strategy.

Our study is limited by not combining behaviors, and we therefore limit our conclusions to the feasibility of the tested behaviors as the sole drivers of migration. It is possible that vertical migration, for example, is a component of a more complex migration strategy, used for example in avoiding strong southward flows or in combination with other behaviors, such as rheotaxis or actively swimming north. Similarly, it is likely that during migration, fish seek, to some extent, to optimize local conditions for growth, such as thermoregulating via vertical migrations (Hinke et al. 2005). Studies conclusively show that yearling Chinook salmon are associated with 
particular environmental characteristics, which indicates some level of behavioral adjustment to local conditions (Bi et al. 2007, Peterson et al. 2010, Burke et al. 2013). However, given the limitations of our data and the added complexity of modeling the effects of multiple interacting behaviors, we limited our analysis to the effects of individual behaviors.

An additional limitation was the testing of only 1 swim speed in simulations of positive rheotaxis. It is possible that these simulations might have matched the observed distributions more accurately using faster swim speeds. However, the migration paths of fish using positive rheotaxis were quite circuitous and often generated distributions with far greater spatial extent than that observed in the catch data.

Of particular importance is a lack of prey resources and predator abundances in our simulations. Unfortunately, spatially explicit data on salmon prey and predator populations do not exist, representing one of the largest gaps in salmon marine ecology. Still, these findings add to the continuing debate on the nature of navigation/orientation cues used by salmon (Quinn \& Groot 1984, Quinn 1991, 2005, Byron \& Burke in press). Future efforts should explore the effect of more complex behaviors, perhaps with multiple components, on fish distribution and incorporate additional data as it becomes available.

The coupling of oceanographic and individualbased models is rapidly becoming an important and efficient way to explore potential behaviors by many species in environments where direct observation is not feasible (North et al. 2009, Kishi et al. 2011, Willis 2011, Byron \& Burke in press). While outside the scope of this work, we recognize a growing need to characterize the effects of modeling uncertainty in both hydrodynamic (Putman \& He 2013) and individualbased models (Simons et al. 2013) and to understand the repercussions of various behavioral rules (Wilson et al. 2013). Nevertheless, we demonstrated the utility of the combined Eulerian-Lagrangian approach in finding support for certain migration behaviors (and sensory capabilities) and clear evidence against other behaviors. As hydrodynamic models improve and collections of empirical data on animal distribution and physiology expand, application of these tools will contribute greatly to our understanding of migration ecology. Moreover, such tools are critical to evaluating the implications of behavioral adjustments to climate-driven changes in the ocean, such as responses to changes in predator or prey distributions, and whether the sensory mechanisms animals have evolved will continue to function in an altered environment (Anderson et al. 2013).
Acknowledgements. Chinook salmon catch data were obtained during a survey funded by the Bonneville Power Administration. Many people assisted with the project organization and data collection, including but not limited to E. Casillas, B. Peterson, R. Brodeur, B. Emmett, K. Jacobson, C. Morgan, J. Zamon, B. Beckman, L. Weitkamp, D. Teel, D. Van Doornik, D. Kuligowski, T. Wainwright, J. Fisher, S. Hinton, and C. Bucher. We also thank J. Butzerin, C. Harvey, S. Smith, M. Scheuerell, B. Sanderson, R. Zabel, and 3 anonymous reviewers for their constructive comments on earlier versions of this document.

\section{LITERATURE CITED}

Alerstam T, Chapman JW, Backman J, Smith AD and others (2011) Convergent patterns of long-distance nocturnal migration in noctuid moths and passerine birds. Proc $\mathrm{R}$ Soc Lond B Biol Sci 278:3074-3080

Anderson JJ, Gurarie E, Bracis C, Burke BJ, Laidre KL (2013) Modeling climate change impacts on phenology and population dynamics of migratory marine species. Ecol Model 264:83-97

Arendt JD (1997) Adaptive intrinsic growth rates: an integration across taxa. Q Rev Biol 72:149-177

Baptista AM, Zhang YL, Chawla A, Zulauf M, and others (2005) A cross-scale model for 3D baroclinic circulation in estuary-plume-shelf systems: II. Application to the Columbia River. Cont Shelf Res 25:935-972

Baptista A, Howe B, Freire J, Maier D, Silva CT (2008) Scientific exploration in the era of ocean observatories. Comput Sci Eng 10:53-58

> Beamish RJ, Mahnken C (2001) A critical size and period hypothesis to explain natural regulation of salmon abundance and the linkage to climate and climate change. Prog Oceanogr 49:423-437

Bi HS, Ruppel RE, Peterson WT (2007) Modeling the pelagic habitat of salmon off the Pacific Northwest (USA) coast using logistic regression. Mar Ecol Prog Ser 336:249-265

Bivand RS, Pebesma EJ, Gómez-Rubio V (2013) Applied spatial data analysis with R. Springer, New York, NY

> Booker DJ, Wells NC, Smith IP (2008) Modelling the trajectories of migrating Atlantic salmon (Salmo salar). Can J Fish Aquat Sci 65:352-361

> Bracis C, Anderson JJ (2012) An investigation of the geomagnetic imprinting hypothesis for salmon. Fish Oceanogr 21:170-181

Brady J (1982) Biological timekeeping, Vol 14. Cambridge University Press, Cambridge

Brochier T, Ramzi A, Lett C, Machu E, Berraho A, Freon P, Hernandez-Leon S (2008) Modelling sardine and anchovy ichthyoplankton transport in the canary current system. J Plankton Res 30:1133-1146

Brodeur RD, Fisher JP, Emmett RL, Morgan CA, Casillas E (2005) Species composition and community structure of pelagic nekton off Oregon and Washington under variable oceanographic conditions. Mar Ecol Prog Ser 298: 41-57

Burke BJ, Liermann MC, Teel DJ, Anderson JJ (2013) Environmental and geospatial factors drive juvenile Chinook salmon distribution during early ocean migration. Can J Fish Aquat Sci 70:1167-1177

- Burla M, Baptista AM, Casillas E, Williams JG, Marsh DM (2010a) The influence of the Columbia River plume on the survival of steelhead (Oncorhynchus mykiss) and 
Chinook salmon (Oncorhynchus tshawytscha): a numerical exploration. Can J Fish Aquat Sci 67:1671-1684

Burla M, Baptista AM, Zhang YL, Frolov S (2010b) Seasonal and interannual variability of the Columbia River plume: a perspective enabled by multiyear simulation databases. J Geophys Res 115:C00B16, doi:10.1029/2008JC 004964

Byron CJ, Burke BJ (in press) Salmon ocean migration models suggest a variety of population-specific strategies. Rev Fish Biol Fish

CMOP (2013) Virtual Columbia River. Center for Marine and Coastal Observation \& Prediction, Portland, OR. Interactive database available from www.stccmop.org/ datamart/virtualcolumbiariver/simulationdatabases (accessed April 2013)

Cross A, Beauchamp D, Moss J, Myers K (2009) Interannual variability in early marine growth, size-selective mortality, and marine survival for Prince William Sound pink salmon. Mar Coast Fish 1:57-70

> Dittman A, Quinn T (1996) Homing in Pacific salmon: mechanisms and ecological basis. J Exp Biol 199:83-91

- Emmett RL, Brodeur RD, Orton PM (2004) The vertical distribution of juvenile salmon (Oncorhynchus spp.) and associated fishes in the Columbia River plume. Fish Oceanogr 13:392-402

Friedland KD, Walker RV, Davis ND, Myers KW, Boehlert GW, Urawa S, Ueno Y (2001) Open-ocean orientation and return migration routes of chum salmon based on temperature data from data storage tags. Mar Ecol Prog Ser 216:235-252

Good SP, Dodson JJ, Meekan MG, Ryan DAJ (2001) Annual variation in size-selective mortality of Atlantic salmon (Salmo salar) fry. Can J Fish Aquat Sci 58:1187-1195

- Grimm V, Berger U, Bastiansen F, Eliassen S and others (2006) A standard protocol for describing individualbased and agent-based models. Ecol Model 198:115-126

Grimm V, Berger U, DeAngelis DL, Polhill JG, Giske J, Railsback SF (2010) The ODD protocol: a review and first update. Ecol Model 221:2760-2768

Groot C (1965) On the orientation of young sockeye salmon (Oncorhynchus nerka) during their seaward migration out of lakes. Behaviour Suppl 14:I-VII, 1-198

Hartt AC, Dell MB (1986) Early oceanic migrations and growth of juvenile Pacific salmon and steelhead trout. Bull Int North Pac Fish Comm 46:1-105

> Healey MC (1982) Timing and relative intensity of sizeselective mortality of juvenile chum salmon (Oncorhynchus keta) during early sea life. Can J Fish Aquat Sci 39: 952-957

Hewett SW, Johnson BL (1992) Fish bioenergetics model 2, Vol WIS-SG-92-250. University of Wisconsin, Sea Grant Institute, Madison, WI

Hickey BM, Royer TC (2001) California and Alaska currents.

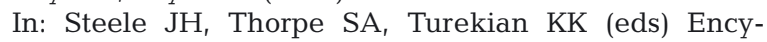
clopedia of ocean sciences. Academic Press, Oxford, p 368-379

- Hickey B, Geier S, Kachel N, MacFadyen A (2005) A bidirectional river plume: the Columbia in summer. Cont Shelf Res 25:1631-1656

> Hickey BM, Kudela RM, Nash JD, Bruland KW and others (2010) River influences on shelf ecosystems: introduction and synthesis. J Geophys Res 115:C00B17, doi:10.1029/ 2009JC005452

> Hinke JT, Foley DG, Wilson C, Watters GM (2005) Persistent habitat use by Chinook salmon Oncorhynchus tshawyt- scha in the coastal ocean. Mar Ecol Prog Ser 304:207-220

> Kirschvink JL, Walker MM, Chang SB, Dizon AE, Peterson KA (1985) Chains of single-domain magnetite particles in Chinook salmon, Oncorhynchus tshawytscha. J Comp Physiol A 157:375-381

Kishi MJ, Ito S, Megrey BA, Rose KA, Werner FE (2011) A review of the NEMURO and NEMURO.FISH models and their application to marine ecosystem investigations. J Oceanogr 67:3-16

> Lacroix GL, McCurdy P (1996) Migratory behaviour of postsmolt Atlantic salmon during initial stages of seaward migration. J Fish Biol 49:1086-1101

Lohmann KJ, Lohmann CMF, Putman NF (2007) Magnetic maps in animals: nature's GPS. J Exp Biol 210:3697-3705

> MacCready P, Banas NS, Hickey BM, Dever EP, Liu Y (2009) A model study of tide- and wind-induced mixing in the Columbia River estuary and plume. Cont Shelf Res 29: 278-291

> Mork KA, Gilbey J, Hansen LP, Jensen AJ and others (2012) Modelling the migration of post-smolt Atlantic salmon (Salmo salar) in the northeast atlantic. ICES J Mar Sci 69: 1616-1624

> Moss JH, Beauchamp DA, Cross AD, Myers KW, Farley EV, Murphy JM, Helle JH (2005) Evidence for size-selective mortality after the first summer of ocean growth by pink salmon. Trans Am Fish Soc 134:1313-1322

North EW, Gallego A, Petitgas P (2009) Manual of recommended practices for modelling physical-biological interactions during fish early life. ICES Coop Res Rep 295. ICES, Copenhagen

Papi F (2006) Navigation of marine, freshwater and coastal animals: concepts and current problems. Mar Freshw Behav Physiol 39:3-12

Pastor A, Artieda J (eds) (1996) Time, internal clocks and movement. Elsevier Science, Amsterdam

Pearcy WG (1992) Ocean ecology of north Pacific salmonids. Washington Sea Grant Program, Seattle, WA

> Peterson WT, Morgan CA, Fisher JP, Casillas E (2010) Ocean distribution and habitat associations of yearling coho (Oncorhynchus kisutch) and Chinook (O. tshawytscha) salmon in the northern California Current. Fish Oceanogr 19:508-525

PFEL (Pacific Fisheries Environmental Laboratory) (2013) OceanColor Web. NOAA CoastWatch Program and NASA's Goddard Space Flight Center, Pacific Grove, CA. Available at http://coastwatch.pfel.noaa.gov (the 'Chlorophyll-a, Aqua MODIS, NPP, 005 degrees, Global, Science Quality*' dataset was downloaded on 13 March 2012)

Python Software Foundation (PSF) (2013) Python programming language. Python Software Foundation, available at www.python.org

> Putman NF, He RY (2013) Tracking the long-distance dispersal of marine organisms: sensitivity to ocean model resolution. J R Soc Interface 10:20120979

> Putman NF, Lohmann KJ, Putman EM, Quinn TP, Klimley AP, Noakes DL (2013) Evidence for geomagnetic imprinting as a homing mechanism in Pacific salmon. Curr Biol 23:312-316

Quinn T (1980) Evidence for celestial and magnetic compass orientation in lake migrating sockeye salmon fry. J Comp Physiol A 137:243-248

$>$ Quinn TP (1991) Models of Pacific salmon orientation and navigation on the open ocean. J Theor Biol 150:539-545 Quinn TP (2005) The behavior and ecology of Pacific salmon 
and trout. American Fisheries Society, Seattle, WA

Quinn TP, Brannon EL (1982) The use of celestial and magnetic cues by orienting sockeye salmon smolts. J Comp Physiol 147:547-552

Quinn TP, Groot C (1983) Orientation of chum salmon (Oncorhynchus keta) after internal and external magnetic-field alteration. Can J Fish Aquat Sci 40:1598-1606

Quinn TP, Groot C (1984) Pacific salmon (Oncorhynchus) migrations: orientation versus random movement. Can J Fish Aquat Sci 41:1319-1324

Quinn TP, Merrill RT, Brannon EL (1981) Magnetic-field detection in sockeye salmon. J Exp Zool 217:137-142

R Development Core Team (2011) R: a language and environment for statistical computing. R Foundation for Statistical Computing, Vienna

Simons RD, Siegel DA, Brown KS (2013) Model sensitivity and robustness in the estimation of larval transport: a study of particle tracking parameters. J Mar Syst 119-120:19-29

Sogard SM (1997) Size-selective mortality in the juvenile stage of teleost fishes: a review. Bull Mar Sci 60: 1129-1157

Thorstad EB, Whoriskey F, Uglem I, Moore A, Rikardsen AH, Finstad B (2012) A critical life stage of the Atlantic salmon Salmo salar: behaviour and survival during the smolt and initial post-smolt migration. J Fish Biol 81: 500-542

> Tomaro LM, Teel DJ, Peterson WT, Miller JA (2012) When is bigger better? Early marine residence of middle and upper Columbia River spring Chinook salmon. Mar Ecol Prog Ser 452:237-252

Tucker S, Trudel M, Welch DW, Candy JR and others (2011) Life history and seasonal stock-specific ocean migration of juvenile Chinook salmon. Trans Am Fish Soc 140: 1101-1119

Walker MM, Quinn TP, Kirschvink JL, Groot C (1988) Production of single-domain magnetite throughout life by sockeye salmon, Oncorhynchus nerka. J Exp Biol 140: 51-63

Editorial responsibility: L. Asbjørn Vøllestad, Oslo, Norway
Walker MM, Diebel CE, Haugh CV, Pankhurst PM, Montgomery JC, Green CR (1997) Structure and function of the vertebrate magnetic sense. Nature 390:371-376

> Waples RS, Teel DJ, Myers JM, Marshall AR (2004) Lifehistory divergence in Chinook salmon: historic contingency and parallel evolution. Evolution 58:386-403

> Ware DM (1978) Bioenergetics of pelagic fish: theoretical change in swimming speed and ration with body size. J Fish Res Board Can 35:220-228

> Weitkamp L (2010) Marine distributions of Chinook salmon from the west coast of North America determined by coded wire tag recoveries. Trans Am Fish Soc 139: $147-170$

Weitkamp LA, Bentley P, Litz MNC (2012) Seasonal and interannual variation in juvenile salmonids and associated fish assemblage in open waters of the lower Columbia River estuary. Fish Bull 110:426-450

Willis J (2011) Modelling swimming aquatic animals in hydrodynamic models. Ecol Model 222:3869-3887

> Willis J, Hobday AJ (2007) Influence of upwelling on movement of southern bluefin tuna (Thunnus maccoyii) in the Great Australian Bight. Mar Freshw Res 58:699-708

Wilson RP, Griffiths IW, Legg PA, Friswell MI and others (2013) Turn costs change the value of animal search paths. Ecol Lett 16:1145-1150

Wiltschko R, Wiltschko W (1995) Magnetic orientation in animals. Springer, Berlin

> Woillez M, Poulard JC, Rivoirard J, Petitgas P, Bez N (2007) Indices for capturing spatial patterns and their evolution in time, with application to European hake (Merluccius merluccius) in the Bay of Biscay. ICES J Mar Sci 64: 537-550

> Yu H, Bi H, Burke B, Lamb J, Peterson W (2012) Spatial variations in the distribution of yearling spring Chinook salmon off Washington and Oregon using COZIGAM analysis. Mar Ecol Prog Ser 465:253-265

Zhang Y, Baptista A (2008) SELFE: a semi-implicit Eulerian-Lagrangian finite-element model for cross-scale ocean circulation. Ocean Model 21:71-96

Submitted: August 15, 2013; Accepted: October 9, 2013 Proofs received from author(s): December 20, 2013 